\title{
Associated risk factors of underweight among under-five children in Ethiopia using multilevel ordinal logistic regression model
}

\author{
Nigussie Adam Birhan ${ }^{1}$, Denekew Bitew Belay ${ }^{2}$
}

\begin{abstract}
1. Department of Statistics, Mekdela Amba University, Tulu Awuliya, Ethiopia.
2. Department of Statistics, Bahir Dar University, Bahir Dar, Ethiopia.
\end{abstract}

\begin{abstract}
Background: Malnutrition is associated with both under nutrition and over nutrition which causes the body to get improper amount of nutrients to maintain tissues and organ function. Under nutrition is the result of insufficient intake of food, poor utilization of nutrients due to illnesses, or a combination of these factors. The purpose of this study was to identify associated risk factors and assess the variation of underweight among under-five children of different regions in Ethiopia. Methods: Ethiopian Demography and Health Survey (EDHS-2016) weight-to-age data for under-five children is used. In order to achieve the objective of this study; descriptive, single level and multilevel ordinal logistic regression analysis were used.

Results: From a total of 8935 children about $8.1 \%$ were severely underweight, $17.1 \%$ were moderately underweight and $74.8 \%$ were normal. The test of heterogeneity suggested that underweight varies among region and multilevel ordinal model fit data better than single level ordinal model.

Conclusion: Educational level of mother, religion, birth order, type of birth, sex of child, mother body mass index, birth size of child, existence of diarrhea for last two weeks before survey, existence of fever for last two weeks before survey, duration of breast feeding, age child and wealth index had significant effect on underweight among under-five children in Ethiopia. The finding revealed that among the fitted multilevel partial proportional odds model, the random intercept model with fixed coefficients is appropriate to assess the risk factors of underweight among under-five children in Ethiopia. The findings of this study have important policy implications. The government should work closely with both the private sector and civil society to teach women to have sufficient knowledge, awareness and mechanisms of improving under-five underweight for children's wellbeing.
\end{abstract}

Keywords: Underweight, Partial proportional odds model, Multilevel partial proportional odds model, under-five children. DOI: https://dx.doi.org/10.4314/ahs.v21i1.46

Cite as: Birhan NA, Belay DB. Associated risk factors of underweight among under-five children in Ethiopia using multilevel ordinal logistic regression model. Afri Health Sci. 2021;21(1):362-72. https:/ / dx.doi.org/10.4314/ahs.v21i1.46

\section{Background of study}

Nutrition is a process by which individual achieve their physical and mental growth throughout their life cycle ${ }^{1}$. Adequate nutrition is important in early childhood to ensure healthy growth, learn new skills, neurological and mental development, think critically, contribute to their communities, and give children a better start in their life ${ }^{2}$.

Malnutrition is associated with both under nutrition and over nutrition which causes the body to get improper amount of nutrients to maintain tissues and organ function ${ }^{3,4}$. Malnutrition is the main health prob-

\section{Corresponding author:}

Denekew Bitew Belay,

Department of Statistics, Bahir Dar University,

Bahir Dar, Ethiopia.

Email: Denekew.t.h@gmail.com, denekewb2020@gmail.com lem in developing countries and it account nearly $45 \%$ of children death and $11 \%$ loss of GDP every year.

Under nutrition is the result of insufficient intake of food, poor utilization of nutrients due to illnesses, or a combination of these factors. It is occurred due to significant deficiencies in any or all form of the energy, protein, or essential vitamins, minerals caused by a range of factors ${ }^{6,7}$. It costs the economy of the world about 2 to 3 percent of GDP in every year. ${ }^{8}$ The prevalence of underweight among under five years children were used to measure the burden of malnutrition ?

Under nutrition remains a serious problem in many developing countries. It affects over 815 million children and cause of death for more than half of children. Around 195 million under-five children were affects by malnutrition; among those $90 \%$ were live in sub Saharan Africa and South Asia. Ethiopia is one of these countries with the highest prevalence of under-five mortality. At least $53 \%$ of children death can be caused directly or indirectly by malnutrition ${ }^{10}$.

(C) 2021 Birhan NA et al. Licensee African Health Sciences. This is an Open Access article distributed under the terms of the Creative commons Attribution License (https://creativecommons.org/licenses/BY/4.0), which permits unrestricted use, distribution, and reproduction in any medium, provided the original work is properly cited. 
In last the decades, Ethiopia planned to reduce child under nutrition, but significant improvement cannot obtain still due to multidimensional and complex factors. Yearly, under nutrition is causes the mortality of $24 \%$ of the children ${ }^{11}$.

A number of studies have been conducted to identify risk factors related to underweight among under five children in Ethiopia by using binary logistic regres$\operatorname{sion}^{12-14}$ and multilevel binary logistic regression ${ }^{15,16}$. However, binary logistic regression classifies underweight in to two categories to fulfill requirements of binary logistic regression. In this study the authors consider ordered classification of under nutrition to see the severity of children nutritional status in Ethiopia. Therefore, the objective of this study is to identify associated risk factors and assess the variation of underweight among under-five children of different regions in Ethiopia using multilevel ordinal logistic regression model.

\section{Methods}

\section{Source of data}

The source of data for this study was Ethiopian Demographic and Health Survey (EDHS 2016) which was obtained from Central Statistical Agency (CSA) under the auspices of the Ministry of Health. The survey was conducted from January 18, 2016 to June 27, 2016 based on a nationally representative sample that provides estimates at the national and regional levels.

EDHS sample was selected using a stratified, two-stage cluster design and enumeration areas were the sampling units for the first stage.

\section{Response variable}

The response variable of the study was underweight which was measured by weight for age Z-score. Weight and age measurements of children were converted into Z-scores based on the National Center for Health Statistics (NCHS) reference population recommended by the World Health Organization (WHO). Underweight can be categorized into three groups: Severely underweight (Z-score $<-3.00)$, moderately underweight (and normal (Z-Score -2.00). From the anthropometrics measures, Authors use weight-for-age to analysis underweight of children's. Weight-for-age is a composite index of height-for-age and weight-for-height and it is overall indicator of population's nutritional health. It takes into account both chronic and acute malnutrition and has a high positive predictive value as indicator of child malnutrition ${ }^{17,18}$.

\section{Risk factors}

The risk factors included in this study are grouped in to socio-economic, demographic, health, environmental and community factors.

Socio-economic risk factors are: - mother educational level, occupational status of mother, household wealth index, and duration of breast feeding status

Demographic risk factors are:- age of child, sex of child, marital status of mother, number of household member, age of mother at first birth, type of birth, Birth order, birth size and religion of mother.

Environmental and community risk factors are: region, place of residence, toilet facility for household, and source of drinking water for household.

Health related risk factors are: - mother body mass index, existence of diarrhea in the two weeks before survey, existence of fever in the two weeks before survey, and existence of cough in the two weeks before survey.

\section{Statistical models}

To analyze underweight among under-five children descriptive, cross tabulation, single level and multilevel ordinal logistic regression model techniques have been applied. In this study chi-square was applied to investigate the association between the underweight and each risk factor. Single level ordinal logistic regression models were conducted to identify the significant risk factors of underweight among under-five children in Ethiopia. Those models were proportional odds model, generalized ordered logit model, partial proportional odds model, continuation ratio model, adjacent-categories model and stereo type model ${ }^{19-21}$. Then other advanced models were applied.

\section{Testing of parallel lines}

Ordinal logistic regression assumes that the coefficients that describe the relationship between the lowest versus all higher categories of the response variable are the same as those that describe the relationship between the next lowest category and all higher categories. This is called the proportional odds assumption. The test of parallelism contains -2log - likelihood for the constrained model, the model that assumes the planes or surfaces are parallel and -2log - likelihood for the general model, the model that assumes planes or surfaces are separated. The chi-square statistic is the log-likeli- 
hood difference between the two models. If the lines or planes are parallel, the observed significance level for the change should be large, the parallel model is adequate $^{22}$.

If the proportional odds assumption is not met, there are several options: the first is to collapse two or more levels, particularly if some of the levels have small sample size. The second is do bivariate logistic analyses, to see if there is one particular independent variable that is operating differently at different levels of the dependent variables. This can be done in various ways, including adjacent and global methods. The third is to use the partial proportional odds model. The last option is to use multinomial logistic regression ${ }^{23}$.

In this study, single level ordinal logistic regression were extends to Multilevel Partial Proportional Odds Model (PPOM) to analyze the relationship between the underweight among under five years children and each of the independent variable which are included in the model and to compare variation with regard to underweight among and within geographical region of Ethiopia.

Multilevel model is used to allow not only independent variables at any level of hierarchical structure but also at least one random effect above level one group ${ }^{24}$. Multilevel ordinal logistic regression model is the analysis of hierarchical and ordinal dependent variable ${ }^{25}$. In this study, the clustering of the data points within geographical regions offers a natural 2-level hierarchical structure of the data, i.e. children are nested within regions. There are nine regions and two city administrations used in 2016 EDHS. Therefore, eleven geographical regions have been used for this study. The data were analyzed using STATA 14.0 and SPSS 21 software. Model I (Empty model): This model is used as the baseline model for future model comparison and estimates the overall average of the outcome variables across all subjects and between-groups and with-in group variances. It was fitted without risk factors other than an intercept. According to 25 multilevel random intercept model for ordinal response variable using the logit link for the cumulative probabilities of being at or below a particular category of $\mathrm{k}$ for the ith child and $\mathrm{jth}$ region is given as follow:

$$
\eta_{i j}=\operatorname{logit}\left(\pi_{k i j}\right)=\log \left(\frac{\pi\left(y_{i j} \leq k\right)}{\pi\left(y_{i j}>k\right)}\right)=\alpha_{k}-\beta_{o j}
$$

Where, $\beta_{0 j}=\gamma_{00}+\mu_{0 j}$

Result becomes

$\eta_{i j}=\operatorname{logit}\left(\pi_{k i j}\left(y_{i j} \leq k\right)\right)=\alpha_{k}-\gamma_{00}-\mu_{0 j}$

Where, $\gamma_{00}$ is the overall logit of being at or below a particular underweight across regions and it set zero since the cut off points $\alpha_{k}$ estimated. Then the overall null model becomes

$\eta \_\mathrm{ij}=\operatorname{logit}\left(\pi \_\mathrm{kij}\left(\mathrm{y} \_\mathrm{ij} \leq \mathrm{k}\right)\right)=\alpha \_\mathrm{k}-\mu \_0 \mathrm{j}$

Where, $\mu_{-} 0 \mathrm{j} \sim \mathrm{N}\left(0, \sigma_{-} \mu 0^{\wedge} 2\right)$ and it is random term of regional level. Thus, $\sigma_{\mu 0}^{2}$ measures regional variations of under-five children underweight and also known as random intercept variance.

\section{Intra class correlation coefficient (ICC)}

Intra class correlation coefficient is used as assessment of how much variations in the response categories lie at the level two (region level). The intra class correlation coefficient indicates the proportion of the variance explained by the grouping structure in the population. Its value is between 0 and 1 . When the value is near to 0 , multilevel model does not fit the data well. Whereas, if the value is large it shows that multilevel analysis required to handle this variation. When logistic model is used the residual at level one (child level) are assumed to follow the standard logistic distribution with mean 0 and variance $\frac{\pi^{2}}{3}=3.29^{25,26}$. It is expressed as:

$$
I C C=\frac{\sigma_{\mu 0}^{2}}{\sigma_{\mu 0}^{2}+\frac{\pi^{2}}{3}}
$$

$\sigma_{\mu 0}^{2}$ is the variance of the higher level(regions).

Model II (Random Intercept Model): It is a model which includes level one risk factors in empty model. The intercept is allowed to vary randomly across regions and the slope for risk factors to be fixed to zero. In this study, multilevel partial proportional odds model is applied to relax the proportional odds assumption. Multilevel partial proportional odds model is the extension of partial proportional odds model which allows one or more independent variables have different effect on $\mathrm{K}-1$ cumulative logits ${ }^{27}$. The model is given as:

$\eta_{i j}=\operatorname{logit}\left(\pi_{k i j}\right)=\log \left(\frac{\pi\left(y_{i j} \leq k\right)}{\pi\left(y_{i j}>k\right)}\right)=\alpha_{k}-\left(\beta_{0 j}+\sum_{c=1}^{p} \beta_{c j} x_{c i j}+\sum_{h=1}^{q} v_{k h} w_{h i j}\right)$

Hence,

$\beta_{0 j}=\gamma_{00}+\mu_{0 j}, \beta_{1 j}=\gamma_{10}, \beta_{2 j}=\gamma_{20}, \ldots, \beta_{p j}=\gamma_{p 0}$

Now the equation is written as:

$$
\eta_{i j}=\operatorname{logit}\left(\pi_{k i j}\left(y_{i j} \leq k\right)\right)=\alpha_{k}-\left(\sum_{c=1}^{p} \gamma_{c 0} x_{c i j}+\sum_{h=1}^{q} v_{k h} w_{h i j}+\mu_{0 j}\right)
$$

Where, $\alpha_{k}-\left(\sum_{c=1}^{p} \gamma_{c 0} x_{c i j}+\sum_{h=1}^{q} v_{k h} w_{h i j}\right)$ is the fixed part of the model, $\mu_{-} 0 \mathrm{j}$ is the intercept variation of the model, $x_{1 i j}, x_{2 i j}, \ldots, x_{p i j}$ are the fixed risk factors which satisfies proportional odds assumption and $\gamma_{-} 10, \gamma_{-} 20, \ldots, \gamma_{-}$ p0 are the coefficients of the fixed risk factors. w_hij is 
$h \mathrm{x} 1$ vector containing the value of observation ij of the set of $h$ covariates for which proportional odds is not assumed and is $v_{k h \mathrm{hx}} 1$ vector of regression coefficient associated with $w_{h i j}$ and it contains category $\mathrm{k}$, due to this $\mathrm{h}$ covariates are allowed to vary across $\mathrm{K}-1$.

Random Coefficient Model: This is used to assess whether the slope of any of the explanatory variables has a significant variance component between the regions. This implies that the coefficients of explanatory variables are random at level two.

According to 27 multilevel partial proportional odds model for random coefficient model is given as:

$\eta_{i j}=\operatorname{logit}\left(\pi_{k i j}\right)=\log \left(\frac{\pi\left(y_{i j} \leq k\right)}{\pi\left(y_{i j}>k\right)}\right)=\alpha_{k}-\left(\beta_{0 j}+\sum_{c=1}^{p} \beta_{c j} x_{c i j}+\sum_{h=1}^{q} v_{k h} w_{h i j}\right)$

Where,

$\beta_{0 j}=\gamma_{00}+\mu_{0 j}, \beta_{1 j}=\gamma_{10}+\mu_{1 j}, \beta_{2 j}=\gamma_{20}+\mu_{2 j}, \ldots, \beta_{p j}=\gamma_{p 0}+\mu_{p j}$

Thus, the model becomes

$\eta_{i j}=\operatorname{logit}\left(\pi_{k i j}\left(y_{i j} \leq k\right)\right)=\alpha_{k}-\left(\sum_{c=1}^{p} \gamma_{c 0} x_{c i j}+\sum_{h=1}^{q} v_{k h} w_{h i j}+\mu_{0 j}+\sum_{c=1}^{p} \mu_{c j} x_{c i j}\right)$

Where, ${ }^{\alpha_{k}}-\left(\sum_{c=1}^{p} \gamma_{c 0} x_{c i j}+\sum_{h=1}^{q} w_{h i j} v_{k h}\right)$ is the fixed part of the model, $\mu_{0 j}+\sum_{c=1}^{p} \mu_{c j} x_{c i j}$ is the random part of the model, $\alpha \_\mathrm{k}$ is the cut point of the model, $\mu_{0 j}$ is intercept variation of the model, $\mu_{-} 1 j, \mu \_2 j, \ldots, \mu \_p j$ slope variation of the model, $\gamma_{-} 10, \gamma_{-} 20, \ldots, \gamma_{-} \mathrm{p} 0$ are the coefficients of the risk factors. $w_{h i j}$ is $\mathrm{h} \times 1$ vector containing the value of observation ij of the set of $h$ covariates for which proportional odds is not assumed and $v_{k h}$ is hx1 vector of regression coefficient associated with $w_{h i j}$ and it contains category $\mathrm{k}$, due to this $\mathrm{h}$ covariates are allowed to vary across $\mathrm{K}-1$.

\section{Results \\ Descriptive analysis}

The analysis was based on 8935 under-five children, among those $74.8 \%, 17.1 \%$ and $8.1 \%$ were normal, moderately underweight and severely underweight respectively in Ethiopia. From Table1 underweight varies from region to region. The highest percentage of severely underweight is observed in Afar (17.02\%) and moderately underweight in Benishangul Gumiz $(22.37 \%)$. Whereas, the smallest percentage of severely underweight $(0.25 \%)$ and moderately underweight $(4.23 \%)$ is observed in Addis Ababa. Children living rural areas were moderately and severely underweight with $(18.70 \%)$ and $(9.09 \%)$ respectively. The prevalence of children who were born from non-educated mothers were severely $(10.15 \%)$ and moderately $(19.75 \%)$ underweight. Similarly, children who were born from poor families were severely $(11.49 \%)$ and moderately $(20.48 \%)$ underweight. The highest percentage of severely underweight was found for 4 and above birth order $(9.74 \%)$ and the lowest percentage was found in first birth order $(5.95 \%)$. The percentage of severely underweight for multiple births were (16.34\%) and single birth $(7.91 \%)$. The prevalence of severely underweight for male were $(8.47 \%)$ and female $(7.72 \%)$. Children who had been affected by diarrhea during the Last two weeks before the survey date were severely underweight $(10.54 \%)$ and moderately underweight (18.67\%). 
Table 1: Results of descriptive summary for risk factors of underweight among under-five children in Ethiopia based on EDHS, 2016.

\begin{tabular}{|c|c|c|c|c|c|c|}
\hline \multirow[t]{2}{*}{ Variable } & \multirow[t]{2}{*}{ Categories } & \multicolumn{3}{|c|}{ Underweight } & \multirow[b]{2}{*}{$\begin{array}{l}\text { Total } \\
\text { count }\end{array}$} & \multirow{2}{*}{$\begin{array}{l}\text { Person chi } \\
\text { square(p- } \\
\text { value) }\end{array}$} \\
\hline & & $\begin{array}{l}\text { Normal } \\
(\%)\end{array}$ & $\begin{array}{l}\text { Moderately } \\
\text { underweight } \\
(\%)\end{array}$ & $\begin{array}{l}\text { Severely } \\
\text { underweight } \\
(\%)\end{array}$ & & \\
\hline \multirow[t]{11}{*}{ Region } & Tigray & 76.67 & 18.45 & 4.88 & 943 & \multirow{11}{*}{$\begin{array}{l}298.05 \\
(<0.001)\end{array}$} \\
\hline & Afar & 61.11 & 21.87 & 17.02 & 846 & \\
\hline & Amhara & 71.14 & 20.69 & 8.17 & 894 & \\
\hline & Oromia & 77.55 & 17.79 & 6.66 & 1381 & \\
\hline & Somali & 73.25 & 17.61 & 9.15 & 1170 & \\
\hline & Benishangul & 65.62 & 22.37 & 12.01 & 733 & \\
\hline & SNNPR & 78.59 & 14.90 & 6.51 & 1121 & \\
\hline & Gambela & 80.29 & 13.08 & 6.63 & 558 & \\
\hline & Harari & 80.17 & 14.16 & 5.66 & 459 & \\
\hline & Addis Ababa & 95.52 & 4.23 & 0.25 & 402 & \\
\hline & Dire Dawa & 73.36 & 17.99 & 8.64 & 428 & \\
\hline \multirow[t]{2}{*}{ Residence } & Urban & 86.17 & 10.16 & 3.67 & 1634 & \multirow{2}{*}{$\begin{array}{l}140.04 \\
(<0.001)\end{array}$} \\
\hline & Rural & 72.21 & 18.70 & 9.09 & 7301 & \\
\hline \multirow{3}{*}{$\begin{array}{l}\text { Mother } \\
\text { education }\end{array}$} & No education & 70.10 & 19.75 & 10.15 & 5695 & \multirow{3}{*}{$\begin{array}{l}221.04 \\
(<0.001)\end{array}$} \\
\hline & Primary & 80.27 & 14.38 & 5.35 & 2316 & \\
\hline & Secondary \&higher & 89.72 & 7.90 & 2.38 & 924 & \\
\hline \multirow[t]{2}{*}{ Toilet } & No & 69.04 & 20.21 & 10.75 & 3999 & \multirow{2}{*}{$\begin{array}{l}134.22 \\
(<0.001)\end{array}$} \\
\hline & Yes & 79.40 & 14.65 & 5.96 & 4936 & \\
\hline Religion & Orthodox & 78.52 & 16.16 & 5.31 & 2710 & 75.62 \\
\hline & Muslim & 71.39 & 18.32 & 10.28 & 4415 & $(<0.001)$ \\
\hline & Other & 77.35 & 15.69 & 6.96 & 1810 & \\
\hline Wealth index & Poor & 68.03 & 20.48 & 11.49 & 4776 & 321.63 \\
\hline & Middle & 75.62 & 18.09 & 6.29 & 1288 & $(<0.001)$ \\
\hline & Rich & 85.58 & 11.15 & 3.27 & 2871 & \\
\hline marital status & Married & 74.75 & 17.14 & 8.10 & 8366 & 0.004 \\
\hline & Single & 74.87 & 17.05 & 8.08 & 569 & $(0.998)$ \\
\hline Mother & No work & 74.11 & 17.11 & 8.78 & 5249 & 7.98 \\
\hline occupation & Had work & 75.69 & 17.17 & 7.14 & 3686 & $(0.018)$ \\
\hline Birth order & First & 79.83 & 14.22 & 5.95 & 1765 & 63.68 \\
\hline & $2-3$ & 76.95 & 16.07 & 6.97 & 2868 & $(<0.001)$ \\
\hline & $4 \&$ above & 71.22 & 19.04 & 9.74 & 7302 & \\
\hline Birth type & Single & 75.03 & 17.06 & 7.91 & 8733 & 22.09 \\
\hline & Multiple & 63.37 & 20.30 & 16.34 & 202 & $(<0.001)$ \\
\hline Sex child & Male & 73.56 & 17.97 & 8.47 & 4568 & 7.22 \\
\hline & Female & 76.02 & 16.26 & 7.72 & 4367 & $(0.027)$ \\
\hline Birth size & Small & 67.01 & 20.86 & 12.13 & 2498 & 142.53 \\
\hline & Average & 75.88 & 16.99 & 7.14 & 3768 & $(<0.001)$ \\
\hline & Large & 80.44 & 13.86 & 5.70 & 2668 & \\
\hline Diarrhea & No & 75.28 & 16.93 & 7.78 & 7901 & 12.64 \\
\hline & Yes & 70.79 & 18.67 & 10.54 & 1034 & $(0.002)$ \\
\hline Fever & No & 75.28 & 16.71 & 8.01 & 7654 & 8.12 \\
\hline & Yes & 71.66 & 19.67 & 8.67 & 1281 & $(0.017)$ \\
\hline Cough & No & 74.86 & 17.10 & 8.05 & 7445 & 0.27 \\
\hline & Yes & 74.30 & 17.32 & 8.39 & 1490 & $(0.875)$ \\
\hline Number of & 4 \& less & 77.90 & 15.41 & 6.69 & 2421 & 21.34 \\
\hline house hold & $5-6$ & 74.50 & 16.95 & 8.54 & 3079 & $(<0.001)$ \\
\hline member & 7 and above & 72.78 & 18.52 & 8.70 & 3435 & \\
\hline Body mass & Thin & 65.31 & 22.37 & 12.32 & 2110 & 205.95 \\
\hline index & Normal & 76.07 & 16.53 & 7.40 & 5983 & $(<0.001)$ \\
\hline & Overweight & 89.19 & 8.31 & 2.49 & 842 & \\
\hline Age child & Less than 6 & 88.27 & 7.07 & 4.66 & 1202 & 210.25 \\
\hline & $6-11$ & 83.27 & 10.85 & 5.88 & 765 & $(<0.001)$ \\
\hline & $12-23$ & 74.32 & 16.75 & 8.93 & 1803 & \\
\hline & $24-35$ & 70.56 & 19.22 & 10.22 & 1722 & \\
\hline & $36-47$ & 70.87 & 20.57 & 8.55 & 1672 & \\
\hline & $48-59$ & 70.13 & 21.80 & 8.07 & 1771 & \\
\hline Mother age at & $18 \&$ less & 72.79 & 18.60 & 8.61 & 4436 & 18.39 \\
\hline $1^{\text {st }}$ birth & $>18$ & 76.71 & 15.69 & 7.60 & 4499 & $(<0.001)$ \\
\hline Duration of & Ever breast & 72.17 & 19.35 & 8.47 & 4614 & \\
\hline breast feeding & Never breast & 72.84 & 18.81 & 8.36 & 335 & $(<0.001)$ \\
\hline & Still breast & 77.92 & 14.43 & 7.65 & 3986 & \\
\hline Source of water & Not improved & 72.06 & 18.48 & 9.46 & 3561 & 25.55 \\
\hline & Improved & 76.55 & 16.24 & 7.20 & 5374 & $(<0.001)$ \\
\hline
\end{tabular}


Table 2: Summary result for multilevel PPOM selection criteria

\begin{tabular}{llll}
\hline Tests & Random intercept only model & $\begin{array}{l}\text { Random intercept with } \\
\text { fixed coefficient model }\end{array}$ & Random coefficient model \\
\hline Log likelihood & -6427.074 & -5947.1673 & -5953.681 \\
Deviance & 12854.148 & 11894.3346 & 11907.362 \\
AIC & 12860.148 & 11978.3346 & 11995.36 \\
BIC & 12881.44 & 12060.28057 & 12307.66 \\
\hline
\end{tabular}

\section{Model Comparisons in Multilevel PPOM}

The deviance value were used to select the best fitting model among the three fitted two-level partial proportional odds models. From Table 2, the deviance of the random intercept only model is 12854.148 and random intercept with fixed coefficient model is 11894.3346 . This indicates that random intercept with fixed coefficient model is better than random intercept only model. And also, the deviance of random coefficient model is 11907.362. This also revealed that random intercept with fixed coefficient model is better than random coefficient model. Hence, random intercept with fixed coefficient model was a better fit as compared to random intercept only model and random coefficient model.

\section{Random Intercept Only Model}

From Table 3 the empty model is considered as a parametric version of assessing heterogeneity of regions variance of the random effect $\left(\sigma_{\mu 0}^{2}=0.596\right.$ ,S.E $=0.345$ ) and the Wald test statistic is (the square of the Z-ratio), $W=(0.596 / 0.345)^{2}=2.98$, which is compared with a chi-squared distribution on 1 degree of freedom is significant and $\sigma_{\mu 0}^{2}=0.596$ indicates that intercept variance across all regions. The hypothesis $H_{0}: \sigma_{\mu 0}^{2}=0$ or there is no cross-regional variation for underweight among under-five children. For this hypothesis, the value of test statistic is 71.99 with p-value $<0.001$. Therefore, the null hypothesis is rejected and there is evidence of heterogeneity or cross regional variation of underweight among under-five children. This shows that an empty model for underweight among under-five children with random effect was better than an empty model for underweight among under-five children without random effect. Therefore, authors conclude that there was significant variation between regions for underweight among under-five children in Ethiopia.

The intra class correlation coefficient (ICC) was obtained from intercept only model $\frac{0.596}{0.596+3.29}=0.153$ which is interpreted as $15.3 \%$ of variation in the underweight can be explained by grouping in regions (higher level units) and the remaining $84.7 \%$ of the variation is explained within region (lower level units).

Table 3: Result of parameter estimate of empty model

\begin{tabular}{lllllll}
\hline & Estimates & Std.Err & $\mathrm{Z}$ & $\mathrm{p}$-value & \multicolumn{2}{l}{ 95\% Conf. Interval } \\
\hline Cut1 & 1.020 & 0.034 & 30.42 & 0.000 & 0.955 & 1.086 \\
cut2 & 2.377 & 0.045 & 52.71 & 0.000 & 2.289 & 2.465 \\
\hline \multicolumn{2}{l}{ Random-effects Parameters } & Estimate & Std.Err & $95 \%$ Conf. Interval \\
\hline Region: & & & & & \\
Var(_cons) & & & 0.596 & 0.345 & 0.192 & 1.854 \\
\hline
\end{tabular}

LR test vs. ologit model: chibar2 (01) $=71.99$ Prob $>=$ chibar2 $=0.0000$

From Table 3 the estimates of the fixed part of the model are 1.020 and 2.377 with p-value $<0.001$ which implies that the average log odds of underweight among under-five children are significantly different from zero. The average probability of under-five children being normal was $\frac{\exp ^{1.020}}{1+e x p^{1.020}}=0.737$ . Whereas, being normal or moderately underweight were $\frac{\exp ^{2.377}}{1+\exp ^{2.377}}=0.915$ which means the chance of being normal was $73.5 \%$ on average and chance of being normal or moderately underweight was $91.5 \%$ on average.

\section{Random Intercept PPOM}

The variance of random effect for random intercept multilevel model (0.093) is smaller than variance of random effect for empty random intercept model (0.596). The reduction of the random effect of the intercept variance is due to the inclusion of fixed risk factors. That is, the fixed independent variables can provide extra predictive value on underweight in each region. 
Table 4: Result of random intercept with fixed coefficients PPOM of underweight among under- five children in Ethiopia using the EDHS 2016.

Risk factors that satisfied parallel line assumptio

\begin{tabular}{|c|c|c|c|c|c|c|c|c|}
\hline Variables & Coeff. & Std.Err & $z$ & p-value & OR & $95 \%$ & I OR & \\
\hline Moedu(ref=no education) & o & & & & 1 & & & \\
\hline Primary & -0.227 & 0.068 & -3.35 & 0.001 & $0.797 *$ & 0.698 & 0.910 & \\
\hline Secondary and above & -0.497 & 0.133 & -3.72 & 0.000 & $0.608 *$ & 0.468 & 0.790 & \\
\hline Moccu(ref=had no work) & o & & & & 1 & & & \\
\hline $\begin{array}{l}\text { Had work } \\
\text { Residence(ref-urban) }\end{array}$ & -0.056 & 0.057 & -0.99 & 0.322 & 0.945 & 0.845 & 1.057 & \\
\hline Residence(ref=urban) & o & & & & 1 & & & \\
\hline Toilet(ref $=$ no $)$ & -0.132 & 0.105 & -1.26 & 0.208 & 0.877 & 0.714 & 1.076 & \\
\hline $\begin{array}{l}\text { Yes } \\
\text { Border(ref=first) }\end{array}$ & -0.081 & 0.064 & -1.26 & 0.207 & 0.922 & 0.814 & 1.046 & \\
\hline $2-3$ & 0.074 & 0.082 & 0.90 & 0.368 & 1.077 & 0.916 & 1.265 & \\
\hline $\begin{array}{l}4 \text { and above } \\
\text { Btype(ref-single birth) }\end{array}$ & 0.229 & 0.092 & 2.49 & 0.013 & $1.257^{*}$ & 1.050 & 1.505 & \\
\hline Multiple birth & o & & & & 1 & & & \\
\hline Sexchild(ref=-male) & $\begin{array}{l}0.700 \\
0\end{array}$ & 0.157 & 4.45 & 0.000 & $\begin{array}{l}2.013 * \\
1\end{array}$ & 1.479 & 2.740 & \\
\hline $\begin{array}{l}\text { Female } \\
\text { Birthsize (ref=large) }\end{array}$ & $\begin{array}{l}-0.165 \\
0\end{array}$ & 0.051 & -3.25 & 0.001 & $\begin{array}{l}0.848 * \\
1\end{array}$ & 0.767 & 0.936 & \\
\hline Average & 0.276 & 0.065 & 4.28 & 0.000 & $1.318 *$ & 1.162 & 1.496 & \\
\hline $\begin{array}{l}\text { Small } \\
\text { Diarrhea }(\text { ref }=\text { no })\end{array}$ & $\begin{array}{l}0.142 \\
0\end{array}$ & 0.069 & 9.29 & 0.000 & $1.900 *$ & 1.659 & 2.175 & \\
\hline $\begin{array}{l}\text { Yes } \\
\text { Fever(ref=no) }\end{array}$ & 0.253 & 0.082 & 3.10 & 0.002 & $1.288 *$ & 1.097 & 1.511 & \\
\hline $\begin{array}{l}\text { Yes } \\
\text { BMI(ref=thin) }\end{array}$ & $\begin{array}{l}0.154 \\
0\end{array}$ & 0.075 & 2.05 & 0.040 & $1.167 *$ & 1.007 & 1.352 & \\
\hline $\begin{array}{l}\text { Normal } \\
\text { Over weight }\end{array}$ & -0.463 & 0.058 & -8.02 & 0.000 & $0.630 *$ & 0.562 & 0.705 & \\
\hline Water(ref=not improved) & -1.057 & 0.129 & -8.18 & 0.000 & $0.347 *$ & 0.270 & 0.448 & \\
\hline $\begin{array}{l}\text { Improved } \\
\text { NoHH(ref=less than 5) }\end{array}$ & $\begin{array}{l}0 \\
0.097 \\
0\end{array}$ & 0.056 & 1.75 & 0.080 & $\begin{array}{l}1 \\
1.102 \\
1\end{array}$ & 0.988 & 1.229 & \\
\hline $\begin{array}{l}5-6 \\
\text { Above } 6\end{array}$ & $\begin{array}{l}-0.027 \\
-0.053\end{array}$ & $\begin{array}{l}0.075 \\
0.084\end{array}$ & $\begin{array}{l}-0.36 \\
-0.63\end{array}$ & $\begin{array}{l}0.716 \\
0.528\end{array}$ & $\begin{array}{l}0.973 \\
0.948\end{array}$ & 0.840 & 1.127 & \\
\hline Durbreast(ref $=$ ever breast) & $\begin{array}{l}-0.033 \\
0\end{array}$ & & & & 1 & 0.004 & & \\
\hline Never breast & 0.105 & 0.133 & 0.79 & 0.429 & 1.111 & 0.856 & 1.441 & \\
\hline Moth-age(ref $=18$ \& less) & 0.310 & 0.078 & 3.94 & 0.000 & $1.363 *$ & 1.169 & 1.590 & \\
\hline Greater than 18 & 0.008 & 0.052 & 0.15 & 0.883 & 1.008 & 0.910 & 1.116 & \\
\hline \multicolumn{9}{|c|}{ Risk factors that does not satisfied parallel line assumption } \\
\hline \multirow{2}{*}{\multicolumn{9}{|c|}{$\begin{array}{l}\text { Normal versus (moderately underweight and severely underw } \\
\text { Agechild(ref-less than } 6 \text { ) }\end{array}$}} \\
\hline & & & & & & & & \\
\hline $6-11$ & 0.415 & 0.137 & & 3.04 & 0.002 & $1.514 *$ & 1.158 & 1.981 \\
\hline $12-23$ & 1.026 & 0.110 & & 9.36 & 0.000 & $2.790^{*}$ & 2.251 & 3.459 \\
\hline 24-35 & 1.381 & 0.118 & & 11.68 & 0.000 & $3.979 *$ & 2.251 & 3.459 \\
\hline $36-47$ & 1.448 & 0.127 & & 11.38 & 0.000 & $4.255 *$ & 3.317 & 5.463 \\
\hline $48-59$ & 1.550 & 0.130 & & 11.91 & 0.000 & $4.711 *$ & 3.651 & 6.078 \\
\hline Windex $(r e f=$ poor $)$ & o & & & & & 1 & & \\
\hline Middle & -0.251 & 0.082 & & -3.07 & 0.002 & $0.778 *$ & 0.663 & 0.913 \\
\hline Rich & -0.610 & 0.086 & & -7.06 & 0.000 & $0.543 *$ & 0.458 & 0.643 \\
\hline Religion(ref $=$ orthodox $)$ & o & & & & & 1 & & \\
\hline Muslim & 0.285 & 0.093 & & 3.08 & 0.002 & $1.330 *$ & 1.110 & 1.595 \\
\hline Other & 0.278 & 0.108 & & 2.58 & 0.010 & $1.320^{*}$ & 1.069 & 1.631 \\
\hline Constant & -3.289 & 0.485 & & -6.78 & 0.000 & $0.037 *$ & 0.014 & 0.097 \\
\hline \multicolumn{9}{|c|}{ (Normal and moderately underweight) versus severely underweight } \\
\hline Agechild(ref=less than 6$)$ & o & & & & & 1 & & \\
\hline 6-11 & 0.255 & 0.208 & 1.2 & & 0.220 & 1.290 & 0.858 & 1.941 \\
\hline $12-23$ & 0.723 & 0.162 & 4.4 & & 0.000 & $2.061 *$ & 1.498 & 2.832 \\
\hline 24-35 & 1.009 & 0.167 & 6.0 & & 0.000 & $2.743 *$ & 1.978 & 3.804 \\
\hline $36-47$ & 0.889 & 0.177 & 5.0 & & 0.000 & $2.433 *$ & 1.719 & 3.442 \\
\hline $48-59$ & 0.925 & 0.179 & 5.1 & & 0.000 & $2.522 *$ & 1.774 & 3.582 \\
\hline Windex(ref=poor) & o & & & & & 1 & & \\
\hline Middle & -0.437 & 0.130 & -3 & & 0.001 & $0.646^{*}$ & 0.501 & 0.834 \\
\hline Rich & -0.877 & 0.129 & -6 & & 0.000 & $0.416^{*}$ & 0.323 & 0.536 \\
\hline Religion(ref $=$ orthodox $)$ & o & & & & & 1 & & \\
\hline Muslim & 0.593 & 0.124 & 4.7 & & 0.000 & $1.809^{*}$ & 1.419 & 2.307 \\
\hline Other & 0.494 & 0.148 & 3.3 & & 0.001 & $1.639 *$ & 1.226 & 2.192 \\
\hline Constant & -0.150 & 0.686 & -0. & & 0.827 & 0.861 & 0.224 & 3.307 \\
\hline Random effect parameter & & Estime & & & Std.Err & & & \\
\hline \multicolumn{9}{|l|}{ Level 2(region) } \\
\hline Var (region): & & 0.093 & & & 0.050 & & & \\
\hline
\end{tabular}


In Table 4, multilevel PPOM revealed that mother education level, birth order, birth size, sex of child, birth type, body mass index of mother, duration of breast feeding status, age of children, house hold wealth index and religion of mother, existence of diarrhea and fever last week before survey date were significantly associated with underweight among under five children. From the significant variable age of child, house hold wealth index and religion of mother were failed the assumption of proportional odds model.

The odds of severely underweight for child from mother who had primary education were $0.797(\mathrm{OR}=0.797$, 95\% CI: $0.698-0.910)$ and secondary and above education were 0.608 (OR $=0.608,95 \%$ CI: 0.468-0.790) times lower than the odds of severely underweight for child from mother who had no education. The odds of having severely underweight for children with birth order 4 and above were 1.257 (OR=1.257, 95\% CI: 1.0501.505) times higher than the odds of severely underweight for children with first birth.

Children having a multiple birth was 2.013 times (OR= 2.013, 95\% CI: 1.479-2.740) more likely to severely underweight than those having single birth. Male children were 1.179 times $(\mathrm{OR}=0.848,95 \% \mathrm{CI}$ : 0.767-0.936) more likely to be severely underweight than females. The odds of severely underweight for child born with average size were 1.318 (OR=1.318, $95 \%$ CI: 1.162-1.496) and smaller than average size were $1.900(\mathrm{OR}=1.900$, 95\% CI: 1.659-2.175) times higher than the odds of severely underweight for child born with larger than average size. The odds of severely underweight for under-five children who had diarrhea in the last two weeks before date of survey were $1.288(\mathrm{OR}=1.288,95 \% \mathrm{CI}$ : 1.079-1.511) times higher than the odds of severely underweight for children those who had no diarrhea in the last two weeks before date of survey. Children who had fever in the last two weeks before the survey time were 1.167 times (OR=1.167, $95 \% \mathrm{CI}: 1.007-1.352)$ more likely to be severely underweight than had no fever.

The odds of severely underweight for child from mother who had normal body mass index were 0.630 $(\mathrm{OR}=0.630,95 \% \mathrm{CI}: 0.562-0.705)$ times and overweight body mass index were $0.347(\mathrm{OR}=0.347,95 \%$ CI: $0.270-0.448$ ) times the odds of severely underweight for child from mother who had thin body mass index. The odds of severely underweight for child who still breast feed were 1.363 (OR=1.363, CI: 1.169-1.590) times the odds of severely underweight for child who had ever breast feed.

When there is a variable which does not satisfied parallel line assumption the interpretation is in each cut points separately. The odds of moderately and severely underweight for child with age group 6-11, 12-23, 24-35, 3647, and 48-59 were 1.514 (OR=1.514, 95\% CI: 1.158 1.981), 2.790 (OR=2.790, 95\% CI: 2.251-3.459), 3.979 $(\mathrm{OR}=3.979,95 \% \mathrm{CI}: 2.251-3.459), 4.255(\mathrm{OR}=4.255$, $95 \%$ CI: 3.317-5.463), and $4.711(\mathrm{OR}=4.711,95 \%$ CI:3.651-6.078) times the odds of moderately or severely underweight with age group less than 6 respectively. However, the odds of severely underweight for child with age group 12-23, 24-35, 36-47 and 48-59 were $2.061(\mathrm{OR}=2.061,95 \% \mathrm{CI}: 1.498-2.832), 2.743$ $(\mathrm{OR}=2.743,95 \%$ CI:1.978-3.804), $2.433(\mathrm{OR}=2.433$, 95\% CI: 1.719-3.442), and 2.522( OR=1.774, 95\% CI: 1.774-3.582) times the odds of severely underweight for child age group less than 6 respectively. The odds of moderately or severely underweight for children who reside from family with middle wealth index were $0.778(\mathrm{OR}=0.778,95 \% \mathrm{CI}: 0.663-0.913)$ times and rich wealth index were $0.543(\mathrm{OR}=0.543,95 \% \mathrm{CI}$ : 0.450 , $0.643)$ times the odds of moderately or severely underweight for child born from poor wealth index family. The odds of severely underweight for child who resided in middle wealth index family were $0.646(\mathrm{OR}=$ $0.646,95 \%$ CI: 0.501-0.834) and rich wealth index family were $0.416(\mathrm{OR}=0.416,95 \% \mathrm{CI}$ : 0.323-0.536) times the odds of severely underweight for child who resided in poor family controlling for other variables in the model and random effect at level two.

\section{Discussion}

This study attempted to identify determinants of underweight among under-five children in Ethiopia using EDHS 2016. Authors' findings reveal that among 8935 children, $8.1 \%$ and $17.1 \%$ were severely and moderately underweight respectively in Ethiopia. Authors used brant test and model selection criteria to select the better model among the fitted single level ordinal logistic regression model. Partial proportion odds model was the most appropriate and better model to analyzed underweight among under five children. With the help of chi-square test, covariates included in the study were significantly associated with underweight except existence of cough two weeks before survey and marital status at $25 \%$ significance. The significant variables were included in multivariable analysis. Multilevel partial proportional odds model technique was applied to analyze risk factors and variation of underweight within and among geographical regions of Ethiopia. The finding revealed that educational level of mother, religion, birth order, type of birth, sex of child, mother body mass 
index, birth size of child, existence of diarrhea for last two weeks before survey, existence of fever for last two weeks before survey, duration of breast feeding, age of the child and house-hold wealth index were significantly associated with underweight and there was significant variation between regions on underweight among under-five children in Ethiopia.

The finding of this study revealed that educational level of mothers had a significant effect with underweight. Children who were born from educated mothers are less risk on underweight in line with other studies ${ }^{28,29}$. Similarly, as birth order increases the risk of underweight also increase. This study is supported by a studies conducted by ${ }^{30,31}$. The current study found that the risk of underweight among under-five children were significantly associated with type of birth. Underweight of children having multiple births were high relative to single birth. This study is similar with the previous study ${ }^{32}$. This study revealed that female child has low risk of being underweight. This study is in lined with other studies ${ }^{31,33,34}$. The result of this study also suggested that Small size children at birth were more severely underweight as compared to large size children. This finding is consistent with other study ${ }^{35}$. The finding of this study also showed that children who had fever two weeks before survey date were significantly vulnerable to underweight than those who had not. This finding is consistent with other studies ${ }^{30,36}$. Similarly, children who had diarrhea two weeks before survey date were more risk of underweight. This has been confirmed by different studies ${ }^{13,14}$. This study showed that women having high body mass index were less likely to be in higher levels of underweight among under-five children as opposed to lower levels of underweight. This result is consistent with the result of studies ${ }^{30,37}$. Children whose breast feeding status is still were more risks for underweight as compared to ever breast feeding. This finding is consistent with other studies ${ }^{18,38}$.

In this study age of child was found to be significantly associated with underweight, as age of child increases the risk of being underweight increases. This finding seemed to be consistent with other studies ${ }^{10,12,29,39}$. This study also revealed that the odds of severely underweight of children were relatively lower for children belonging to rich category of the wealth index as compared to poor. This finding is consistent with other studies 9,15 . The result of this study indicated that children born from other religions follower have high- er chances of experiencing underweight compared to those Orthodox Christianity followers. This is consistent with the study ${ }^{40}$.

\section{Conclusion}

The significant risk factors for underweight among under five children analyzed using PPOM were residence, region, education level of mother, birth order, type of birth, sex of child, mother BMI, birth size of child, diarrhea for last two weeks before survey, fever for last two weeks before survey and duration of breast feeding by fulfilling brant test (proportional odds assumption). However, age of the child, house hold wealth index and religion failed the proportional odds assumption.

The covariates educational level of mother, religion, birth order, type of birth, sex of child, mother body mass index, birth size of child, existence of diarrhea for last two weeks before survey, existence of fever for last two weeks before survey, duration of breast feeding, age child and house hold wealth index had significant effect on underweight among under-five children in Ethiopia.

The findings of this study have important policy implications. The government should work closely with both the private sector and civil society to teach women to have sufficient knowledge, awareness and mechanisms of improving under-five underweight to make children very well. Design and implement primary health care and support the house holds to develop their economy.

$\begin{array}{lc}\begin{array}{l}\text { Abbreviations } \\ \text { CSA }\end{array} & \text { Central Statistical Agency } \\ \text { EDHS } & \text { Ethiopian Demographic Health } \\ \text { Survey } & \\ \text { GDP } & \text { Gross Domestic Product } \\ \text { ICC } & \text { Intra-class Correlation Coefficient } \\ \text { NCHS } & \text { National Center for Health Sta- } \\ \text { tistics } & \\ \text { PPOM } & \text { Partial Proportional Odds Model }\end{array}$

Declarations

Ethics approval and consent to participate

Not Applicable.

\section{Consent for publication}

Not applicable.

\section{Availability of data and material}

The datasets have been taken from Ethiopian Central Statistical Agency. 


\section{Funding}

Not applicable.

\section{Competing interests}

The authors declare that they have no competing interests.

\section{Authors' contributions}

NA involved in the study design, performed the data extraction, analyzing and drafted the manuscript; DB involved in study design, advising through each stage and reviewed the manuscript. All authors have read critically and approved the final manuscript.

\section{Acknowledgments}

The authors would like to thanks the Ethiopian Central Statistics Agency for providing us all the relevant secondary data used in this study and Bahir Dar University for its support.

\section{References}

1. Webb P. Nutrition and the Post-2015 Sustainable Development Goals: A Technical Note, 2014, Boston: United Nations Standing Committee on Nutrition.Online. Available at www. unscn. org/files/Publications /... Nutrition/Final_Nutrition $\%$ 20and_the_SDGs. pdf. 2. Haddad LJ et al. Global Nutrition Report 2015: Actions and accountability to advance nutrition and sustainable development. 2015: Intl Food Policy Res Inst.

3. Gamecha RT. Demissie, and A. Admasie, The Magnitude of Nutritional Underweight and Associated Factors Among Children Aged 6-59 Months in Wonsho Woreda, Sidama Zone Southern Ethiopia. The Open Public Health Journal, 2017. 10(1).

4. Ali AM., Batu MM, Kaushik KK. Socio-economic determinants of nutritional status of children in Ethiopia. Int J Sci Res Publications, 2016. 6(3): p. 166-76.

5. Achadi E et al. Global nutrition report 2016: From promise to impact: Ending malnutrition by 2030. 2016: International Food Policy Research Institute.

6. von Grebmer K. et al., 2017 global hunger index: The inequalities of hunger. 2017: Intl Food Policy Res Inst.

7. Dessie Z.B et al. Maternal characteristics and nutritional status among 6-59 months of children in Ethiopia: further analysis of demographic and health survey. BMC Pediatrics, 2019. 19(1): p. 83.

8. IFPRI, Anual Report, 2014.

9. Bacha R, Tadesse M. Bayesian generalized linear model for identifying predictors of child nutritional status in Ethiopia. Biom Biostat Int J, 2019. 8(2): p. 65-74. 10. Temesgen N, Haile A. Determinants of Nutrition- al Status of Under-Five Children in Ethiopia: With Particular Reference to Anelmoworeda, Hadiya Zone, Southern Nations, Nationalities and Peoples Region. Agriculture and Food Sciences Research, 2017. 4(2): p. 45-57. 11. UNICEF, The cost of hunger in Ethiopia. The social and economic impact of child undernourishment in Ethiopia summary report. Addis Ababa: UNICEF, 2014.

12. Haile A, Amboma TA. Children's nutritional status and its determinants in small towns, Sebeta Hawas district, Oromia, Ethiopia. Journal of Food Science and Nutrition, 2018. 1(1): p. 33-47.

13. Fekadu Y et al. Factors associated with nutritional status of infants and young children in Somali Region, Ethiopia: a cross-sectional study. BMC Public Health, 2015. 15(1): p. 846.

14. Brhane G, Regassa N. Nutritional status of children under five years of age in Shire Indaselassie, North Ethiopia: Examining the prevalence and risk factors. Kontakt, 2014. 16(3): p. e161-e170.

15. Alom J, Quddus MA, Islam MA. Nutritional status of under-five children in Bangladesh: a multilevel analysis. Journal of Biosocial Science, 2012. 44(5): p. 525-535.

16. Mohammed A. Socio-economic determinants of nutritional status of children in Ethiopia, 2015, Jimma University.

17. CSA, 2016 Demographic and Health Survey Key Findings 2016.

18. Mohammed S, Asfaw ZG. Bayesian Gaussian regression analysis of malnutrition for children under five years of age in Ethiopia, EMDHS 2014. Archives of Public Health, 2018. 76(1): p. 21.

19. Liu X, Koirala H. Fitting proportional odds models to educational data with complex sampling designs in ordinal logistic regression. Journal of Modern Applied Statistical Methods, 2013. 12(1): p. 26.

20. Agresti A. Categorical data analysis. 2002. Hoboken, New Jersey: John Wiley \& Sons Inc, 2002: p. 267-313.

21. McCullagh P, Nelder JA. Generalized linear models. Vol. 37. 1989: CRC press.

22. O'Connell AA. Logistic regression models for ordinal response variables. Vol. 146. 2006: Sage.

23. Agresti A. Analysis of ordinal categorical data. Vol. 656. 2010: John Wiley \& Sons.

24. Hox JJ, Moerbeek M, Van de Schoot R. Multilevel analysis: Techniques and applications. 2017: Routledge.

25. Liu X. Applied ordinal logistic regression using Stata: From single-level to multilevel modeling. 2015: Sage Publications.

26. Snijders TA. Multilevel analysis, in International encyclopedia of statistical science. 2011, Springer. p. 879882.

African Health Sciences, Vol 21 Issue 1, March, 2021 
27. Hedeker D, Mermelstein R.J. A multilevel thresholds of change model for analysis of stages of change data. Multivariate Behavioral Research, 1998. 33(4): p. $427-$ 455.

28. Adugnga $\mathrm{T}$ et al. Assessment of Nutritional status and Associated factors of children under 5 years of age in Dabat Town, North Gondar, Ethiopia. 2017.

29. Endris NH. Asefa, and L. Dube, Prevalence of malnutrition and associated factors among children in rural Ethiopia. BioMed Research International, 2017. 2017.

30. Takele K. Semi-parametric analysis of children nutritional status in Ethiopia. International Journal of Statistics and Applications, 2013. 3(5): p. 141-154.

31. Gelano TN, Birhan M. Mekonnen. Prevalence of undernutriton and its associated factors among under-five children in Gonder city, NorthWest Ethiopia. Journal of Harmonized Research in Medical Health Science, 2015. 2(4): p. 163-174.

32. Debeko DD, Goshu AT. Nutritional status of under-five children in hawassa zuria district, southern Ethiopia. Am J Health Res, 2015. 3(5): p. 286-92.

33. Abshoko AD et al. Heterogeneity of Children Weight-for-age Variations: Determinants and Consequences of Child Nutritional Status in Ethiopia. British Journal of Mathematics \& Computer Science, 2016. 16(2).

34. Akombi B et al. Stunting, wasting and underweight in sub-Saharan Africa: a systematic review. International
Journal of Environmental Research and Public Health, 2017. 14(8): p. 863.

35. Yilkal M, Kassahun T. Determining Risk Factors of Malnutrition among under - Five Children in Sheka Zone, South West Ethiopia Using Ordinal Logistic Regression Analysis. Public Health Research, 2016. 6(6): p. 161-167.

36. Habyarimana F. Key determinants of malnutrition of children under five years of age in Rwanda: Simultaneous measurement of three anthropometric indices. African Population Studies, 2016. 30(2).

37. Yisak HT. Gobena, F. Mesfin, Prevalence and risk factors for under nutrition among children under five at Haramaya district, Eastern Ethiopia. BMC Pediatrics, 2015. 15(1): p. 212.

38. Yalew BF Amsalu, Bikes D. Prevalence and factors associated with stunting, underweight and wasting: A community based cross sectional study among children age 6-59 months at Lalibela Town, Northern Ethiopia. J Nutr Disorders Ther, 2014. 4(147): p. 2161-0509.1000147. 39. Alemayehu $\mathrm{M}$ et al. Undernutrition status and associated factors in under-5 children, in Tigray, Northern Ethiopia. Nutrition, 2015. 31(7-8): p. 964-970.

40. Das S, Gulshan J. Different forms of malnutrition among under five children in Bangladesh: a cross sectional study on prevalence and determinants. BMC Nutrition, 2017. 3(1): p. 1. 